\title{
Endoscopic Cyclophotocoagulation Combined with Phacoemulsification Increases Risk of Persistent Anterior Uveitis Compared to Phacoemulsification Surgery Alone
}

This article was published in the following Dove Press journal:

Clinical Ophthalmology

Vivek A Koduri

Amit K Reddy

Jennifer L Patnaik

Alan G Palestine

Anne M Lynch

Mina B Pantcheva

Department of Ophthalmology, University of Colorado School of Medicine, Aurora, CO, USA
Correspondence: Mina B Pantcheva Department of Ophthalmology, University of Colorado School of Medicine, 1675 Aurora Court, F73I, Aurora, CO, 80045, USA

Tel $+\mid-720-848-2500$

Fax + I-720-848-4043

Email mina.pantcheva@cuanschutz.edu
Purpose: To evaluate if the addition of endoscopic cyclophotocoagulation (ECP) to uncomplicated phacoemulsification cataract extraction increases the risk of persistent anterior uveitis (PAU) compared to phacoemulsification alone.

Patients and Methods: Retrospective analysis of patients who had either phacoemulsification alone or combined with endoscopic cyclophotocoagulation from January 1, 2014 to December 31, 2017. Visual acuity, intraocular pressure, presence of anterior chamber cells, and steroid usage were analyzed pre- and post-operatively. Patient eyes with a history of uveitis, autoimmune disease, complicated cataract surgery, combined surgery other than ECP, and less than 3 months of follow-up were excluded.

Results: This study consisted of 4423 eyes from 2903 patients, meeting the inclusion criteria (phacoemulsification only group $n=4242$ and phacoemulsification/ECP group $n=181$ eyes). PAU developed in $14.9 \%$ in the phacoemulsification with ECP group compared to $1.7 \%$ who had phacoemulsification alone. White patients had a 17.9 (95\% CI: 7.8-41.1, p<0.0001) increased odds of developing persistent anterior uveitis with a combined procedure compared to phacoemulsification only, while Non-white patients had a 5.8 (95\% CI: 2.8-12.1, p<0.0001) increased odds. Despite the higher odds ratio in White patients, this group had a significantly lower rate of PAU compared to Non-white patients after phacoemulsification/ECP.

Conclusion: The addition of endoscopic cyclophotocoagulation to phacoemulsification significantly increases the risk of developing PAU in the post-operative period compared to phacoemulsification alone.

Keywords: minimally invasive glaucoma surgery, post-operative inflammation

\section{Introduction}

Endoscopic laser cyclophotocoagulation (ECP) decreases aqueous production via direct ablation of the ciliary body. ECP is being increasingly used in combination with cataract surgery in patients with mild to moderate glaucoma. ${ }^{1}$ This combined procedure is convenient for several reasons. ${ }^{2}$ The ECP instrumentation is easily utilized in conjunction with the clear-corneal approach used in modern cataract surgery. ${ }^{3}$ The frequent coexistence of these two age-related eye diseases makes many patients suitable for both procedures to achieve improved vision and IOP control. ${ }^{4,5}$ Studies have shown that using phaco/ECP could reduce the intraocular pressure (IOP) by $17.6 \%$ to $46.9 \%$, and decrease IOP-lowering medications by $21.9 \%$ to $79.7 \%{ }^{6}$ 
Mild inflammation sometimes occurs following uncomplicated phacoemulsification surgery and often resolves with post-operative topical steroids and/or nonsteroidal anti-inflammatory agents. However, some patients, especially African Americans, develop a more chronic or persistent anterior uveitis (PAU) ${ }^{7,8}$ Edminston et al demonstrated that PAU has also been found to occur after combined phaco/ECP, particularly in African Americans. ${ }^{9}$ However, the lack of a control group in this study did not allow for the determination of the relative contribution of the ECP to the development of PAU regardless of race. Our objective in this study was to understand if the addition of ECP to uncomplicated phacoemulsification surgery increases the risk of PAU compared to phacoemulsification alone in patients without other inflammatory diseases.

\section{Patients and Methods}

We performed a retrospective cohort study using a cataract outcomes registry developed by our department at the School of Medicine, University of Colorado. The study received exempt approval from our Institutional Review Board (COMIRB\# 17-0629) and all research conformed to the tenets of the Declaration of Helsinki. Information from the cataract surgery patient records at our institution was reviewed and abstracted by professional research assistants. Data were entered into REDCap (Research Electronic Data Capture). We collected data on demographics, medical history, pre- and post-operative medications, surgical complications, and pre- and post-operative ophthalmic exams. Data acquired were kept anonymized and the exempt status of the research approval did not require a waiver of informed consent or documentation of informed consent.

Patients who underwent phacoemulsification and intraocular lens implantation with or without ECP, between January 1, 2014 and December 31, 2017 were included. We excluded patients with a history of systemic or ocular inflammatory disease, surgery combined with another intraocular procedure (eg minimally invasive glaucoma surgery, vitrectomy), with any intraoperative complications such as zonular dialysis, iris trauma, posterior capsular tear, retained lens particles, vitreous loss, or choroidal hemorrhage. Eyes without 3 months or more post-operative follow-up were excluded. All study charts met the definition for PAU diagnosis. PAU was defined as an anterior chamber cell grade of at least $0.5+$ and/or steroid therapy for 3 months or more post-operatively, with no other etiology found other than the post-operative state, using the Standardization of Uveitis Nomenclature (SUN) Working Group. ${ }^{10}$ If the patient had another intraocular surgery in the 3-month post-operative period (eg retinal detachment repair, IOL exchange, macular hole repair, vitrectomy, epiretinal membrane peel, goniotomy) they were also excluded from the study (15 eyes in the phaco alone and 3 eyes in the phaco/ECP group).

Phacoemulsification was performed using a clear corneal approach. ECP was performed using a standard protocol treating 270 to 300 degrees of ciliary processes. ${ }^{11}$ A continuous duration of $0.25 \mathrm{~W}$ of laser energy was used for each patient. Brand moxifloxacin was either injected intracamerally or applied topically using a collagen shield at the end of the procedure. The post-operative therapy consisted of topical fluoroquinolone, nonsteroidal antiinflammatory agent, and corticosteroid. At week one the topical antibiotic was discontinued. The corticosteroid was either given as difluprednate $0.05 \%$ two times daily for 2 weeks or prednisolone acetate $1 \%$ four times daily for 1 week followed by a 3-week taper (per surgeon preference). All the phaco/ECP patients received prednisolone acetate $1 \%$ and glaucoma medications were restarted according to surgeon discretion. The use of topical steroids was extended if persistent intraocular inflammation was detected beyond the first post-operative month. Patients, in whom macular pathology was suspected due to unexplained diminished visual acuity underwent optical coherence tomography at the physician's discretion.

We collected data on: age, race/ethnicity, sex, surgical complexity, duration of surgery, cumulative dissipated energy (CDE), visual acuity (VA), intraocular pressure (IOP), anterior chamber (AC) cell and corticosteroid regimen at post-operative month three. Self-reported race/ethnicity was defined as White, African American, Hispanic, or other. The grade of AC cell was recorded by the physician using the SUN Working Group criteria. ${ }^{10}$

\section{Statistical Analysis}

Pre-operative, surgical, and post-operative characteristics were compared for eyes that had undergone phacoemulsification alone versus eyes that had phaco/ECP surgeries. Incidence of PAU was determined for phacoemulsification alone versus phaco/ECP stratified by race/ethnic group. Ocular characteristics and PAU were analyzed using logistic regressions with general estimating equations (GENMOD; SAS, Inc., Cary, North Carolina) to account for the intrasubject correlation. Visual acuity was converted to LogMAR to describe means and standard deviations (SD). The odds ratios and 95\% 
confidence intervals were used for measures of association with ECP as the exposure and PAU as the outcome. KaplanMeier survival curves between the two surgical groups were compared for time to resolution and time to no topical steroid therapy with the Log rank test. P values less than 0.05 were deemed statistically significant. SAS version 9.4 software (Cary, North Carolina) was used for the statistical analysis.

\section{Results}

We had 4423 eyes from 2903 patients that met the inclusion criteria for our study. In total, 4242 eyes had phacoemulsification surgery only and 181 eyes had combined phaco/ECP surgery. The clinical and demographic data of the study population in each group are presented in Table 1.

We found a small but statistically significant difference on comparison of pre-operative LogMAR between the phacoemulsification only and phaco/ECP groups (mean of 0.468 (SD 0.52) in phacoemulsification alone versus 0.341 (SD 0.48 ) in phaco/ECP, $\mathrm{p}=0.040$ ) and IOP (mean of 14.6 (SD 3.0) in phacoemulsification alone versus 15.6 (SD 4.9) in phaco/ECP, $p<0.0001)$. The LogMAR was not significantly different between patients with and without PAU at 3-month follow-up in the phacoemulsification only $(\mathrm{p}=0.332)$ or

Table I Clinical and Demographic Characteristics of Eyes in the Phaco Alone and Phaco/ECP Groups

\begin{tabular}{|c|c|c|c|}
\hline & Phaco Alone & Phaco/ECP & p-value \\
\hline Number of eyes & 4242 & 181 & - \\
\hline \multicolumn{4}{|l|}{ Gender } \\
\hline Male & 1790 (42.2\%) & 79 (43.6\%) & \\
\hline Female & 2452 (57.8\%) & $102(56.4 \%)$ & 0.759 \\
\hline \multicolumn{4}{|l|}{ Race/ethnicity } \\
\hline White & 3140 (74.0\%) & 120 (66.3\%) & Reference \\
\hline Non-white & $1102(26.0 \%)$ & 61 (33.7\%) & 0.065 \\
\hline African-American & $349(8.2 \%)$ & 25 (13.8\%) & 0.021 \\
\hline Hispanic & $340(8.0 \%)$ & 20 (11.0\%) & 0.158 \\
\hline Other & $413(9.7 \%)$ & $16(8.8 \%)$ & 0.970 \\
\hline \multicolumn{4}{|l|}{ Age } \\
\hline Mean (SD) & $69.9(9.9)$ & $71.1(10.9)$ & \\
\hline Median & 70.7 & 72.4 & 0.236 \\
\hline $\mathrm{CDE}$ & 3917 & 91 & \\
\hline Mean (SD) & $8.2(7.5)$ & $5.0(3.0)$ & $<0.0001$ \\
\hline Median & 6.1 & 4.6 & \\
\hline Surgery length (mins.) & 3856 & 178 & \\
\hline Mean (SD) & $19.2(10.3)$ & $26.2(8.4)$ & $<0.0001$ \\
\hline Median & 16 & 25 & \\
\hline
\end{tabular}

Note: Bolding represent major study groups.

Abbreviations: $C D E$, cumulative dissipated energy; SD, standard deviation.
phaco/ECP groups $(\mathrm{p}=0.568)$ (Table 2). At 3-month followup, patients who developed PAU had a mean IOP of 14.2 $\mathrm{mmHg}$ (SD 3.2) in the phacoemulsification only and 16.0 $\mathrm{mmHg}$ (SD 5.8) in the phaco/ECP groups, which was not statistically significantly different $(\mathrm{p}=0.104)$.

A total of $72(1.7 \%)$ eyes developed PAU in the phacoemulsification only group, whereas a total of 27 (14.9\%) eyes met the criteria for PAU in the phaco/ECP group ( $\mathrm{p}<0.0001)$ (Table 3).

In stratified analysis, Non-whites had a 5.8 (95\% CI: 2.8-12.1, $\mathrm{p}<0.0001$ ) increased odds of developing PAU following phaco/ECP compared to phacoemulsification alone, and Whites had an even higher increased odds of 17.9 (95\% CI: 7.8-41.1, $\mathrm{p}<0.0001)$ for developing PAU after phaco/ECP. Despite the higher odds ratio in White

Table 2 Pre-Operative and Post-Operative Best-Corrected VA and IOP by Type of Surgery

\begin{tabular}{|c|c|c|c|}
\hline & PAU & No PAU & p-value \\
\hline $\begin{array}{l}\text { Phaco Alone } \\
\text { Pre-operative Logmar, n } \\
\text { Mean (SD) } \\
\text { Median }\end{array}$ & $\begin{array}{l}72 \\
0.543(0.60) \\
0.301\end{array}$ & $\begin{array}{l}4164 \\
0.466(0.5 I) \\
0.30 I\end{array}$ & 0.211 \\
\hline $\begin{array}{l}\text { Post-op Logmar at mo 3, } \mathrm{n} \\
\text { Mean (SD) } \\
\text { Median }\end{array}$ & $\begin{array}{l}70 \\
0.234(0.28) \\
0.176\end{array}$ & $\begin{array}{l}3839 \\
0.205(0.33) \\
0.097\end{array}$ & 0.332 \\
\hline $\begin{array}{l}\text { Pre-operative IOP, n } \\
\text { Mean (SD) } \\
\text { Median }\end{array}$ & $\begin{array}{l}72 \\
15.0(3.1) \\
15.0\end{array}$ & $\begin{array}{l}4100 \\
14.6(3.0) \\
14.0\end{array}$ & 0.327 \\
\hline $\begin{array}{l}\text { Post-op IOP at mo 3, n } \\
\text { Mean (SD) } \\
\text { Median }\end{array}$ & $\begin{array}{l}63 \\
14.2(3.2) \\
14.0\end{array}$ & $\begin{array}{l}3458 \\
13.3(2.7) \\
13.0\end{array}$ & 0.012 \\
\hline \multicolumn{4}{|l|}{ Phaco/ECP } \\
\hline $\begin{array}{l}\text { Pre-operative Logmar, } \mathrm{n} \\
\text { Mean (SD) } \\
\text { Median }\end{array}$ & $\begin{array}{l}27 \\
0.390(0.58) \\
0.301\end{array}$ & $\begin{array}{l}154 \\
0.332(0.47) \\
0.176\end{array}$ & 0.571 \\
\hline $\begin{array}{l}\text { Post-op Logmar at mo } 3, \mathrm{n} \\
\text { Mean (SD) } \\
\text { Median }\end{array}$ & $\begin{array}{l}27 \\
0.276(0.61) \\
0.097\end{array}$ & $\begin{array}{l}148 \\
0.217(0.42) \\
0.097\end{array}$ & 0.568 \\
\hline $\begin{array}{l}\text { Pre-operative IOP, n } \\
\text { Mean (SD) } \\
\text { Median }\end{array}$ & $\begin{array}{l}27 \\
15.7(3.6) \\
16.0\end{array}$ & $\begin{array}{l}153 \\
15.5(5.1) \\
14.0\end{array}$ & 0.866 \\
\hline $\begin{array}{l}\text { Post-op IOP at mo 3, n } \\
\text { Mean (SD) } \\
\text { Median }\end{array}$ & $\begin{array}{l}27 \\
16.0(5.8) \\
14.0\end{array}$ & $\begin{array}{l}137 \\
13.3(3.7) \\
13.0\end{array}$ & 0.011 \\
\hline
\end{tabular}

Note: Bolding represents major study groups.

Abbreviations: VA, visual acuity; IOP, intraocular pressure; SD, standard deviation; $n$, number of eyes. 
Table 3 PAU by Surgery Type and Race/Ethnicity for Study Eyes

\begin{tabular}{|c|c|c|c|c|c|}
\hline & Total Eyes & PAU (n) & Incidence PAU (\%) & Odds Ratio $(95 \% \mathrm{CI})$ & p-value \\
\hline \multicolumn{6}{|c|}{ All race/ethnicities } \\
\hline Phaco alone & 4242 & 72 & $1.7 \%$ & Reference & $<0.000$ I \\
\hline Phaco/ECP & 181 & 27 & $14.9 \%$ & $10.2(5.8-17.7)$ & \\
\hline \multicolumn{6}{|l|}{ White } \\
\hline Phaco alone & 3140 & 23 & $0.7 \%$ & Reference & $<0.000$ I \\
\hline Phaco/ ECP & 120 & 14 & $11.7 \%$ & I7.9 (7.8-4I.I) & \\
\hline \multicolumn{6}{|l|}{ Non-white } \\
\hline Phaco alone & 1102 & 49 & $4.4 \%$ & Reference & $<0.0001$ \\
\hline Phaco/ECP & 61 & 13 & $21.3 \%$ & $5.8(2.8-12.1)$ & \\
\hline \multicolumn{6}{|c|}{ African-American } \\
\hline Phaco alone & 349 & 43 & $12.3 \%$ & Reference & 0.025 \\
\hline Phaco/ECP & 25 & 7 & $28.0 \%$ & $2.8(1.1-6.7)$ & \\
\hline \multicolumn{6}{|l|}{ Hispanic } \\
\hline Phaco alone & 340 & 2 & $0.6 \%$ & Reference & 0.005 \\
\hline Phaco/ECP & 20 & 2 & $10.0 \%$ & $18.8(2.4-\mid 46)$ & \\
\hline \multicolumn{6}{|c|}{ Other race/ethnicity } \\
\hline Phaco alone & 413 & 4 & $1.0 \%$ & Reference & $<0.000$ I \\
\hline Phaco/ECP & 16 & 4 & $25.0 \%$ & $34.1(6.4-181)$ & \\
\hline
\end{tabular}

Note: Bolding represents major study groups.

Abbreviation: PAU, persistent anterior uveitis.

patients, this group had a significantly lower rate of PAU compared to Non-white patients after phaco/ECP. Age, sex, and CDE were not significant risk factors for PAU. As expected, the phaco/ECP cohort had a significantly longer surgery length $(26.2 \pm 8.4$ minutes $)$ in comparison to the phacoemulsification alone group $(19.2 \pm 10.3)$.

The type of post-operative steroid used in the patients who developed PAU after phacoemulsification was not significantly different by race/ethnic group. Among Whites, $17.4 \%$ received prednisolone drops, and $22.4 \%$ of non-white patients received prednisolone drops $(p=0.652)$ as opposed to difluprednate. All patients after phaco/ECP received prednisolone drops in the postoperative period. No eye had granulomatous inflammation. As expected, among eyes with PAU, 74.1\% of the eyes in the phaco/ECP group were on topical alpha-agonist and/or prostaglandin analogue pre-operatively versus $9.0 \%$ of the eyes in the phacoemulsification only group $(p<0.0001)$.

Eighteen of the 72 eyes $(25.0 \%)$ developed postoperative $\mathrm{CME}$ in the phacoemulsification group. One eye of the $27(3.7 \%)$ in the phaco/ECP cohort developed CME post-operatively.

We performed an analysis to compare the time to resolution of PAU between phacoemulsification only and phaco/ECP groups, and the results can be seen in the Kaplan-Meier curves in Figures 1 and 2. No significant differences were observed for the time to resolution of $\mathrm{AC}$ cell $(\mathrm{p}=0.182)$ or the time until patients were taken off topical steroids $(p=0.187)$ between the two groups. These findings did not change when the time to resolution was compared for eyes using difluprednate versus prednisolone drops in the post-operative period in the PAU patients. Twenty-eight eyes ( 5 in the phaco/ ECP and 23 eyes in the phaco alone group) developed chronic, non-resolving PAU beyond 1 year of follow-up. Five eyes ( 3 patients) required the addition of IOP lowering medication. Twelve eyes ( 3 eyes in the phaco/ECP and 10 eyes in the phaco alone group) had PAU still present at 2-year follow-up with three eyes ( 2 patients) requiring additional IOP lowering medication. We did not find a detrimental effect on the best-corrected visual acuity due to the persistent inflammation in the eyes with PAU at one and 2-year follow-up.

\section{Discussion}

Our results showed that the addition of ECP significantly increased the risk of developing PAU after phaco/ECP surgery compared to phacoemulsification alone. We 


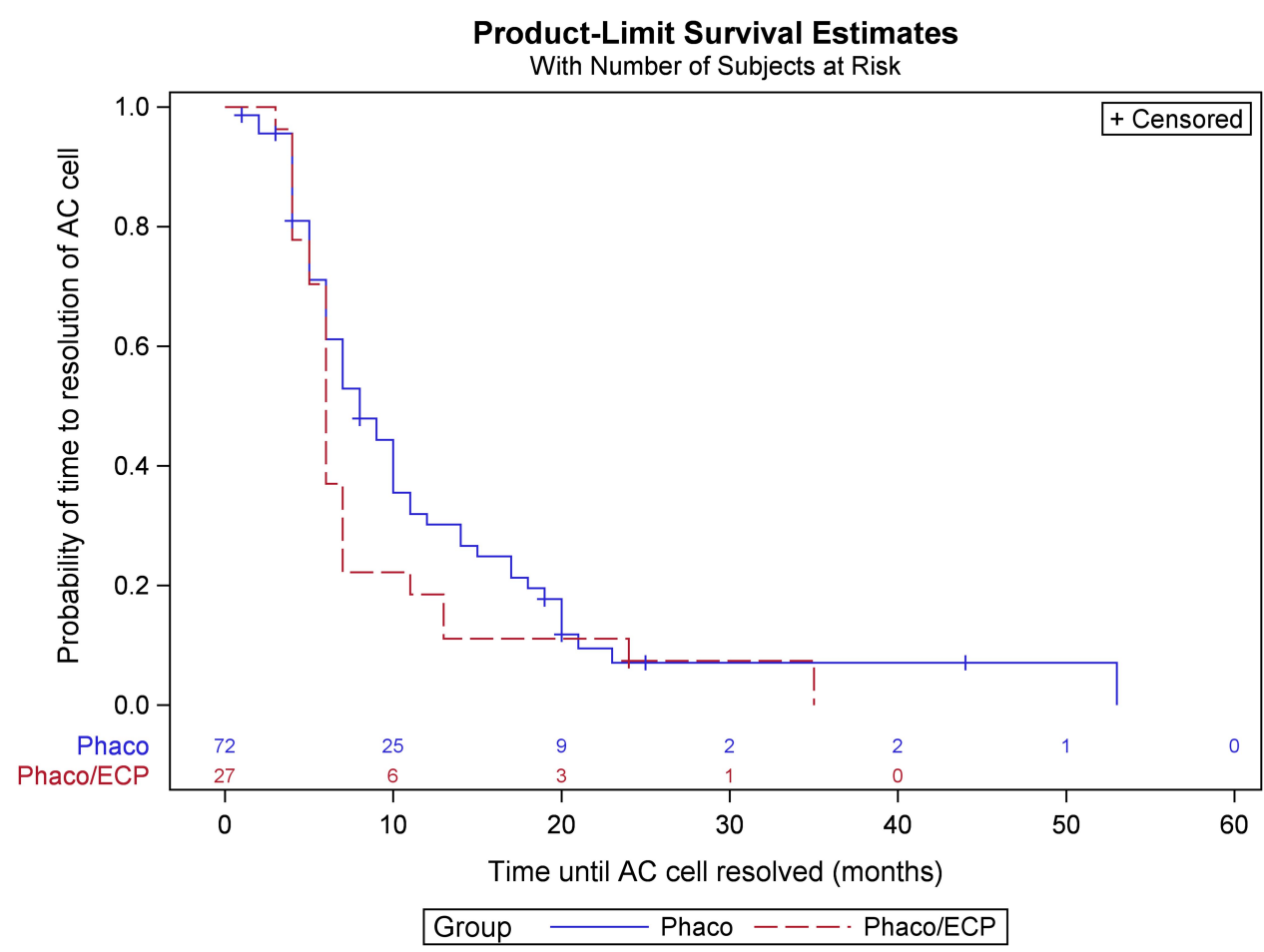

Figure I Product-limit survival estimates curve comparing time to resolution of anterior chamber (AC) cell between phaco only and phaco/ECP groups with PAU.

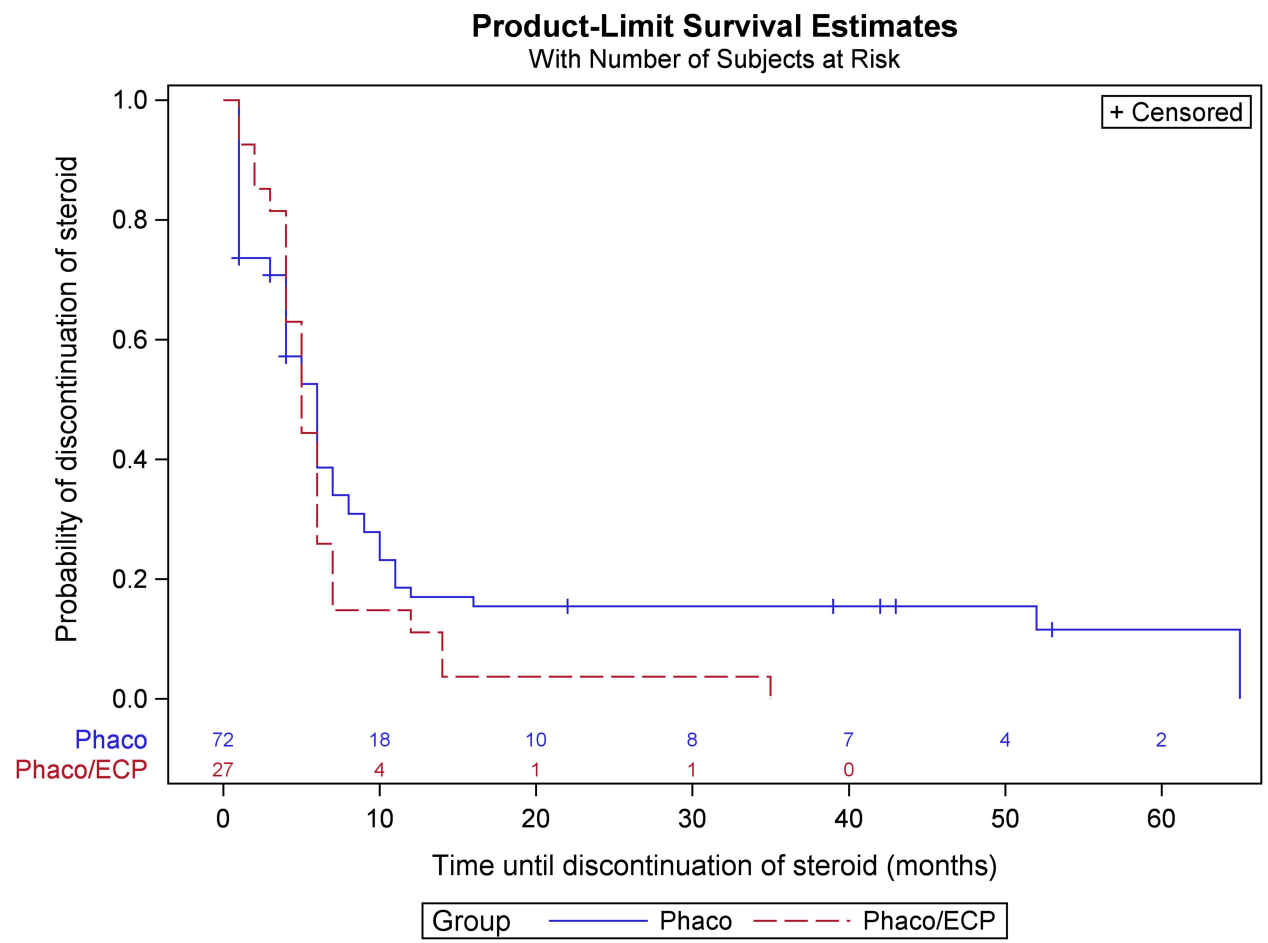

Figure 2 Product-limit survival estimates curve comparing time until patients discontinued the topical steroid drops between phacoemulsification only and phaco/ECP groups with PAU.

suspected this was likely the result of a combination of the additional laser energy delivered into the eye and the inflammatory destruction of ciliary processes triggering a stronger inflammatory response. As expected, the addition of ECP resulted in a longer length of surgery compared to phacoemulsification alone. While it was 
possible that the increased surgical duration could have also contributed to the increased rates of PAU, it was important to note that there was significantly less $\mathrm{CDE}$ used in the phaco/ECP group. As previously reported the higher $\mathrm{CDE}$ and duration of phacoemulsification alone were not significant risk factors for PAU in patients undergoing phacoemulsification only. ${ }^{7}$ In our present study, after adjustment for ECP, CDE and duration of surgery were not associated with PAU.

We also found Non-white patients to have significantly higher rates of PAU after phaco/ECP compared to White patients but this study was underpowered to identify any other role for racial risk factors. In an analysis of phaco/ECP eyes only, there were significantly higher odds of PAU for African American patients, $\mathrm{OR}=2.9(1.0-8.6), \mathrm{p}=0.048$. This was also true for the phacoemulsification alone group, $\mathrm{OR}=19.0 \quad(10.7-33.9)$. This finding supports Reddy et $\mathrm{al}^{7}$ report that PAU is more common after uncomplicated phacoemulsification alone in African Americans. Edmiston et al noted a significantly lower rate of PAU in Whites in comparison to African Americans following phaco/ECP. ${ }^{9}$ The etiology of higher incidence of PAU in Non-white patients is unclear, though it is possible that increased melanin in the eyes might be a contributing factor. Greater absorption of laser energy might be expected when there is more pigment, which would suggest that ECP may cause ciliary body damage in darkly pigmented patients. Melanin has also been shown to possibly play a role in intraocular inflammation. ${ }^{12}$ The possibility of post-ECP transient pigment dispersion masquerading anterior uveitis could be considered, however, PAU is defined as inflammation for at least 3 months. It is unlikely that transient pigment dispersion from the ECP would persist this long and it would not have prompted the use of topical corticosteroids for such a prolonged time.

The complications of prolonged intraocular inflammation have been well described, but post-operative PAU in this study did not affect the final visual outcome in most patients. The majority of PAU patients had inflammation that resolved entirely, with no significant differences in time course to resolution between the phacoemulsification alone or phaco/ECP groups. Interestingly, the KaplanMeier survival curve in Figure 1 seemed to suggest that the PAU resolved more quickly in the phaco/ECP cohort, but this trend was not statistically significant. A subset of patients did go on to have a chronic, non-resolving PAU that required prolonged topical corticosteroid treatment over a year, which could come with associated risks and side effects. ${ }^{13,14}$ Some patients were also noted to have visually significant post-operative CME, though this study was not focused on comparing the relationship between PAU and CME. Only one of the eyes which developed PAU in the phaco/ECP group developed CME postoperatively. This might be contributed to the relatively low number of patients in this group. Berke et al compared phaco/ECP to phaco alone and reported CME to be similar $(0.8 \%$ in the phaco/ECP and $0.7 \%$ in the phaco only group). ${ }^{15,16}$ The ECP Study group demonstrated no difference in angiographic CME in eyes undergoing phaco-ECP versus phaco alone (about $2 \%$ ). ${ }^{17}$

Our study has several limitations due to its retrospective design. The non-uniform immediate postoperative corticosteroid regimen may have resulted in some variability in post-operative inflammation; this did not affect its duration. Inflammation was also treated at the physician's discretion, leading to some variability in the length of steroid treatment, particularly in lowgrade inflammation. We also noted a decrease in the number of ECP procedures performed in African American patients at our institution in 2017, compared to the prior years and thus our study was underpowered to identify any racial/ethnic differences between African Americans, Hispanics, and "other" races. Based on our prior research showing the rates of PAU to be significantly higher for African Americans undergoing ECP, concern for causing PAU and the availability of other minimally invasive glaucoma surgeries is likely the contributing factor for this practice trend. In addition, a significantly higher number of PAU patients were on alpha-agonists and/or prostaglandin analogues preoperatively with the majority continuing these postoperatively in the phaco/ECP cohort, which rarely may cause uveitis. ${ }^{18-23}$ However, we excluded patients with prior uveitis and there are no published research data to suggest these agents contribute to the development of post-operative anterior uveitis.

In summary, there is a significantly higher risk of persistent intraocular inflammation after phacoemulsification surgery with concurrent endoscopic cyclophotocoagulation. The acknowledgement of this additive risk may suggest an alteration of the corticosteroid use when patients undergo phaco/ECP, especially in Non-white patients.

\section{Funding}

Research to Prevent Blindness, Inc. (New York, NY) Unrestricted Grant to the Department of Ophthalmology. 
Frederic C. Hamilton Macular Degeneration Center and the Colorado Clinical \& Translational Sciences Institute (CCSTI).

\section{Disclosure}

None of the authors have any conflicts of interest or proprietary interests related to this manuscript.

\section{References}

1. Siegel MJ, Boling WS, Faridi OS, et al. Combined endoscopic cyclophotocoagulation and phacoemulsification versus phacoemulsification alone in the treatment of mild to moderate glaucoma. Clin Exp Ophthalmol. 2015;43:531-539. doi:10.1111/ceo.12510

2. Sun W, Yu CY, Tong JP. A review of combined phacoemulsification and endoscopic cyclophotocoagulation: efficacy and safety. Int J Ophthalmol. 2018;11(8):1396-1402. doi:10.18240/ ijo.2018.08.23

3. Cohen A, Wong SH, Patel S, et al. Endoscopic cyclophotocoagulation for the treatment of glaucoma. Surv Ophthalmol. 2017;62 (3):357-365. doi:10.1016/j.survophthal.2016.09.004

4. Tham YC, Li X, Wong TY, et al. Global prevalence of glaucoma and projections of glaucoma burden through 2040: a systematic review and meta-analysis. Ophthalmology. 2014;121(11):2081-2090. doi:10.1016/j.ophtha.2014.05.013

5. Klein BE, Klein R, Lee KE. Incidence of age-related cataract over a 10-year interval: the Beaver Dam eye study. Ophthalmology. 2002;109(11):2052-2057. doi:10.1016/S0161-6420(02)01249-6

6. Budenz DL, Gedde SJ. New options for combined cataract and glaucoma surgery. Curr Opin Ophthalmol. 2014;25(2):141-147. doi:10.1097/ICU.0000000000000027

7. Reddy AK, Patnaik JL, Miller DC, et al. Risk factors associated with persistent anterior uveitis after cataract surgery. Am J Ophthalmol. 2019;9394(19):30068.

8. Neatrour K, McAlpine A, Owens TB, et al. Evaluation of the etiology of persistent iritis after cataract surgery. $J$ Ophthal Inflam Infect. 2019;9(1):4. doi:10.1186/s12348-019-0170-2

9. Edmiston AM, SooHoo JR, Seibold LK, et al. Postoperative inflammation after endoscopic cyclophotocoagulation: racial distribution and effect on outcomes. J Glaucoma. 2018;27(3):266-268. doi:10.1097/IJG.0000000000000884

10. Jabs DA, Nussenblatt RB, Rosenbaum JT. Standardization of uveitis nomenclature (SUN) working group. Results of the first international workshop. Am J Ophthalmol. 2005;140:509-516. doi:10.1016/j. ajo.2005.03.057
11. Seibold LK, SooHoo JR, Kahook MY. Endoscopic cyclophotocoagulation. Middle East Afr J Ophthalmol. 2015;22:18-24. doi:10.4103/0974-9233.148344

12. Kaya M, Edward DP, Tessler H, et al. Augmentation of intraocular inflammation by melanin. Invest Ophthalmol Vis Sci. 1992;33 (3):522-531.

13. Musleh MG, Bokre D, Dahlmann-Noor AH. Risk of intraocular pressure elevation after topical steroids in children and adults: a systematic review. Eur $J$ Ophthalmol. 2020;30(5):856-866. doi:10.1177/1120672119885050

14. Chang YS, Weng SF, Chang C, et al. Associations between topical ophthalmic corticosteroids and central serous chorioretinopathy: a Taiwanese population-based study. Invest Ophthalmol Vis Sci. 2015;56(6):4083-4089. doi:10.1167/iovs.14-16360

15. Berke SJ, Sturm RT, Caronia RM, et al. Phacoemulsification combined with endoscopic cyclophotocoagulation (ECP) in the management of cataract and medically controlled glaucoma: a large, long term study. In: American Glaucoma Society 16th Annual Meeting; 2-5 March 2006.; Charleston, SC; 2006.

16. Berke SJ. Endolaser Cyclophotocoagulation in glaucoma management. Tech Ophthalmol. 2006;4:74-81. doi:10.1097/ 00145756-200606000-00008

17. The ECP Study Group. Comparison of phaco/ECP to phaco alone in 1000 glaucoma patients; a randomized, prospective including fluorescein angiography in all patients in both groups. Presented at the ASCRS; June 2002; Philadelphia, PA.

18. Byles DB, Frith P, Salmon JF. Anterior uveitis as a side effect of topical brimonidine. Am J Ophthalmol. 2000;130:287-291. doi:10.1016/S0002-9394(00)00491-8

19. Becker HI, Walton RC, Diamant JI, Zegans ME. Anterior uveitis and concurrent allergic conjunctivitis associated with long-term use of topical $0.2 \%$ brimonidine tartrate. Arch Ophthalmol. 2004;122:1063-1066. doi:10.1001/archopht.122.7.1063

20. Nguyen EV, Azar D, Papalkar D, McCluskey P. Brimonidine-induced anterior uveitis and conjunctivitis: clinical and histologic features. J Glaucoma. 2008;17:40-42. doi:10.1097/IJG.0b013e3181132188

21. Camras CB. CME and anterior uveitis with latanoprost use. Ophthalmology. 1998;105:1978-1981. doi:10.1016/S0161-6420(98) 91103-4

22. Fechtner RD, Khouri AS, Zimmerman TJ, et al. Anterior uveitis associated with latanoprost. Am J Ophthalmol. 1998;126:37-41. doi:10.1016/S0002-9394(98)00071-3

23. Suominen S, Valimaki J. Bilateral anterior uveitis associated with travoprost. Acta Ophthalmol Scand. 2006;84:275-276. doi:10.1111/ j.1600-0420.2005.00601.x
Clinical Ophthalmology

\section{Publish your work in this journal}

Clinical Ophthalmology is an international, peer-reviewed journal covering all subspecialties within ophthalmology. Key topics include: Optometry; Visual science; Pharmacology and drug therapy in eye diseases; Basic Sciences; Primary and Secondary eye care; Patient Safety and Quality of Care Improvements. This journal is indexed on PubMed
Central and CAS, and is the official journal of The Society of Clinical Ophthalmology (SCO). The manuscript management system is completely online and includes a very quick and fair peer-review system, which is all easy to use. Visit http://www.dovepress.com/ testimonials.php to read real quotes from published authors. 